\title{
Tourism industry in the new Europe: trends, policies and challenges
}

\author{
Maria-Irina ANA \\ The Bucharest University of Economic Studies, Bucharest, Romania \\ ana.mariairina@yahoo.com
}

\begin{abstract}
This paper provides an examination of tourism in the New Member States of the European Union from the date of accession until the last year for which data is available (2014), assessing not only the importance of tourism for the New Member States economy, but also the factors and trends that might affect this industry. Predictions for tourism after joining the EU had been confident and the statistical findings confirmed that the outcomes had been to a great extent encouraging and favourable. Considerable research has been devoted to tourism in the developed countries from Europe, the so-called Old Member States, but rather less attention has been paid to tourism in the Central Eastern Europe, the New Member States region. In this regard, the paper will start with an overview of the current state of the literature on this topic, section that precedes a presentation of European bodies and policies in the travel and tourism field. According to The World Bank Database (World Tourism Organization, 2016), the number of international inbound tourists in the countries Newest Members of EU increased on average three times and in many cases this is partly a consequence of the Community's accession policy and the market oriented policies in the new Member States (Enterprise and Industry Directorate-General of the European Commission, 2007). Time series will be analysed in order to identify specific trends in the tourism industry, but also in an attempt to characterize the European integration impact on the New Member States' tourism. Main future challenges and opportunities in the travel and tourism industry will also be sketched, so the paper to better serve not only participants in the academic community and practitioners in the tourism business, but also financial market parties or consultants.
\end{abstract}

Keywords: European tourism, European tourism policies, New Member States, tourism trends, European integration.

\section{Introduction}

In the last two decades three new waves of economic integration took place in Europe (2004, 2007, 2013), enlarging the economic space towards the Central, Eastern and SouthEastern part of Europe. Tourism is one of the service industries that has been highly affected by the evolution of the EU integration process and it is still successfully used as a fail-safe tool to fulfil the ultimate goal of integration and stability.

In this context, the scope of the work is to present an analysis of the tourism sector in the New Member States (NMS-13) of the European Union, looking at its importance for the economy of New Europe, and also at the factors and trends that might affect this industry. The core of the paper is represented by the following research questions regarding the tourism industry in the New Member States of the European Union: How much tourism sector contribute to the New Member States economy? What is the impact of European Union accession on tourism in the New Member States? What trends and factors affect the tourism in the New Member States? Which are the main EU policies in the tourism industry? To fulfil the intended objectives, the paper will be structured as follows: it will start with a brief literature review, section that paves the way for the presentation of European bodies and policies in the travel and tourism field. A third section will focus not 
only on specific trends in the tourism industry, but also on main future challenges and opportunities for the European tourism overall, with a focus on the Central, Eastern SouthEastern region. Indicators such as the number of EU-28 arrivals, number of intra-EU-28 overnight stays, as well as imports and exports in travel will be taken into consideration in order to have a better understanding of the tourism environment in the New Europe. Analysing time series of data and tourists' preferences will enable us to identify specific PICBE | 494 trends in the tourism industry, but also to characterize the European integration impact on the New Member States' tourism.

\section{Context}

Europe is currently the most important continent in terms of both outbound and inbound tourism. According to the latest report from the World Tourism Organization - UNWTO (2016), 51\% of the international tourist arrivals and 36\% of the international tourism receipts were recorded in Europe, $40.3 \%$ of the international tourist arrivals and $3.4 \%$ of the international tourism receipts being attributed to the EU-28.

Although the rest of the EU-28 countries cannot compete with the big key players in the European market, France, Spain, UK, Italy and Germany, according to World Bank statistics (2016), the number of international inbound tourists in the New Member States of the European Union (NMS-13) region increased on average three times. This growth is in many cases attributed to the Community's accession policy and the market oriented policies in the NMS (Enterprise and Industry Directorate-General of the European Commission, 2007). However, the poorer reputation most of the NMS have continues to affect the tourism industry in this region. As per Nicolescu (2008), tourism is one of the most visible aspects of country branding and unquestionably the greatest beneficiary of a favourable image. Even the citizens of some of the NMS-13 tend to have a rather negative perception of their countries. For example, "when reflecting about themselves, Romanians think first about their main weaknesses as a people and the negative individual traits (dishonesty, cowardice, corruption), exacerbated by the economic difficulties of the last decade" (Nicolescu, Paun, Popescu, Draghici, \& Pinzaru, 2007, p. 82). However, even though the interviewed people mentioned the negative aspects first, when they were specifically asked about positive traits, they specified several qualities for which Romanians are already known abroad, such as: hospitality, tolerance, brainpower, having fun like no others or propensity for work, but also thought that foreigners should be aware of the wonderful landscapes, beautiful traditions, tasty food, rich history.

As per the Travel \& Tourism Council (2016), the tourism sector's total contribution to the NMS-13 region GDP is approximately $12 \%$, while the direct contribution of travel and tourism to the NMS is approximately 5\%. Besides, the travel and tourism direct contribution is expected to grow by $2.8 \%$ over the next ten years, which outpaces the total economy in Europe (1.9\% compound annual growth rate).

\section{EU Policies in the Tourism Sector}

Even though the importance of tourism for the European integration process was firstly acknowledged on the $10^{\text {th }}$ of April 1984, it is not until recently that the European Institutions have started to focus on the tourism industry. Only broad strategies and norms were designed in 1984, but this is perceived as an important step forward for the tourism 
industry, on the grounds that it raised Member States' attention to this particular sector, recognised tourism as a independent action and as a valuable tool meant to ease European integration (Morata, 2002). From 2001 on, the Commission published a series of policy initiatives for tourism at EU level. Most of them focused on sustainable tourism and a stronger Union.

Forecasts predict downturns regarding tourism in Europe by 2030. Hence, EU has to PICBE | 495 take measures to remain competitive, to adapt its product offerings to ever-changing tourist preferences, but also to the demographic changes EU-28 will face by 2020 (people over 65year old will count for $20 \%$ of the total EU population) or to the ever-changing information and communication technologies (European Commission, 2010, p. 9). To overcome all these challenges, the European Commission came up with a new framework called "Europe, the world's No. 1 tourist destination - a new political framework for tourism in Europe", initiative that focuses on four main points: "to stimulate competitiveness in the European tourism sector, to promote the development of sustainable, responsible, and high-quality tourism, to consolidate Europe's image as a collection of sustainable, high-quality destinations, to maximise the potential of EU financial policies for developing tourism" (European Commission, 2010, p. 7). The European Parliament adopted this plan in September 2011, while also asking the other European Institutions to develop and encourage different tourism schemes, especially programmes through which to support the small and medium sized enterprises, emphasizing the significance of high-quality tourism, aiming attention at the regional branding, at working together on developing areas such as agro-tourism, gastro-tourism, and EU's cultural, historical or natural heritage.

In this regard, a series of projects and initiatives has been designed, mostly focusing on reducing seasonality's side effects and attracting tourists from regions such as South America, India and China to emerging countries, most of them the NMS of the EU. According to Debyser (2014, p. 6), "21\% of potential tourists from emerging markets (outside of Europe) abandon their plans to travel to Europe due to slow processing of visas", so the European Institutions took note and eased Schengen Area's rules and regulation, as to facilitate tourists flows.

Therefore, it can be concluded that EU Institutions and Organizations are increasingly aware of tourism sector's importance for the whole economy, and for that reason they struggle to improve and maintain EU-28's allure from a touristic point of view. However, cooperation between parties (not only among Member States, but also between these and the EU bodies) is still to be improved. In the sections that follow, we will look at how the EU accession influenced tourism in the NMS and how important is this sector for the NMS' economy.

\section{Methodology}

According to UNWTO (2016), out of the total number of tourists arrivals recorded in Europe in 2014, 80\% were reported within the EU-28 and roughly $15 \%$ of these are attributed to NMS-13, which are, in chronological order from the date of accession, the following: Malta, Cyprus, Estonia, Latvia, Lithuania, Poland, Czech Republic, Slovakia, Slovenia, Hungary (2004), Bulgaria, Romania (2007) and Croatia (2013). For these countries, certain indicators have been extracted and analysed, the main source of data being Eurostat. When information was missing, statistics were collected from the World Tourism Organization and the World Travel and Tourism Council. 
In order to be able to identify specific trends in the tourism industry and to determine the European integration impact on the NMS' tourism, the following indicators were chosen and considered to be pertaining to our purpose:

- Number of Arrivals and Number of Overnight Stays - these two related indicators include visitors entering the economic area of the Member States considered. The numbers of arrivals include tourists and same-day non-resident visitors. PICBE | 496 Additionally, the overnight stays correspond to the number of nights spent by guests, non-resident tourists in all kinds of accommodation establishments (hotels, holiday and other short-stay accommodation, camping grounds, recreational vehicle parks and trailer parks). However, the arrivals of same-day visitors that only spend a few hours in that country (no overnight stay is recorded, the date of arrival and departure being the same) are excluded when counting the number of overnight stays.

- Imports/Exports in Travel - these indicators are very often referred to as "international transactions". Imports in Travel are represented by the expenses tourists undertake while travelling abroad, while tourism exports refer to all the goods and services tourists consume while abroad. Incoming tourists represent tourism exports, and outgoing tourists represent tourism imports.

Firstly, the number of arrivals and overnight stays was considered to be relevant for countries' popularity and attractiveness. Secondly, exports and imports in travel are suitable for sketching economic development, while also reflecting changing trends in destination preferences, or the influence of exchange rates fluctuations. The figures gathered were analysed (both absolute terms and percentages were looked at) and all significant variations were further investigated. We went through any extreme or unusual fluctuation and tried to determine the main causes for the changes. The highest the number of arrivals (or overnight stays) the more popular and attractive that destination. If a country exports a greater value of travel services than it imports, there is a positive, favourable balance in travel. Last, but not least, the impact of EU accession on tourism in the NMS will be assessed by analysing time series, as these are more useful for general trends identification.

\section{Main Statistical Findings}

In the following section, the indicators mentioned and presented above will be analysed. NMS tourism evolution will be sketched, but general trends and challenges will also be identified and discussed.

\section{EU Arrivals and Overnight Stays in the NMS-13}

According to Eurostat Statistics, the number of arrivals from Europe in the EU rose by $16 \%$ in 2014 compared to 2007, from 623.2 million to 723 million persons. The EU arrivals in the NMS for the period 2007-2014 is illustrated year-by-year in Figure 1. It can be easily noticed that the only countries facing downturns in the number of tourists were Cyprus, down 22\% and Slovakia, 19\%. All the other eleven countries saw their number of EU arrivals increasing, which indicates that EU accession played quite a role in the evolution of tourism industry in the region under consideration. Croatia reported the most significant rise, as the number of non-resident tourists went up by 53\% in 2014 compared to 2007 . 
The largest amount of tourists in Cyprus are UK residents, approximately 35\% of the total number of incoming tourists. According to the Statistical Service of Republic of Cyprus (2016), the number of UK residents travelling to Cyprus decreased by $32 \%$ in the period 2007-2014. The economic crisis, the crisis in Lebanon, the terrorist incidents in some European countries, the oil prices increase, the instability of Cyprus Airways, as well as the outdated hotel accommodation and rather poor infrastructure and facilities, the cultural identity related frictions, the one-dimensional tourism type (sea and sun) and the intensive competition are the main factors that affected the tourism industry in Cyprus (Clerides \& Pashourtidou, 2007). In what regards the drop in the tourism sector in Slovakia, it is to a large extent caused by mild winters that led to considerable decreases in ski tourism. Moreover, the global crisis, the conflict in Ukraine, the swings between the surrounding countries' currencies and the Euro, as well as the lower standards of services compared to the neighbourhood countries and the sluggish promotion and marketing techniques that has been in place negatively affected the tourism industry in Slovakia (Weiss, Weiss, Zuzik, \& Kovanic, 2013). The main sources of tourists in Slovakia were Czech Republic, Poland and Germany, and for all these three considerable decreases were reported, the most significant decline being attributed to Poland, from where approximately 80.000 less arrivals were recorded in Slovakia.

On the other hand, the Newest Member of the European Union, Croatia, became popular due to a smart combination of "an increasing number of articles in leading world magazines and other media praising its natural and cultural attractions" (The Miroslav Krleža Institute of Lexicography, n.d.), a large variety of touristic offers, the boost in Foreign and Domestic Investment in tourism and auxiliary infrastructure, as well as the rise in the number of protected tangible and non-tangible objects, parts of the cultural heritage.

\section{Evolution of EU arrivals in the NMS-13 by country of destination 2007-2014}

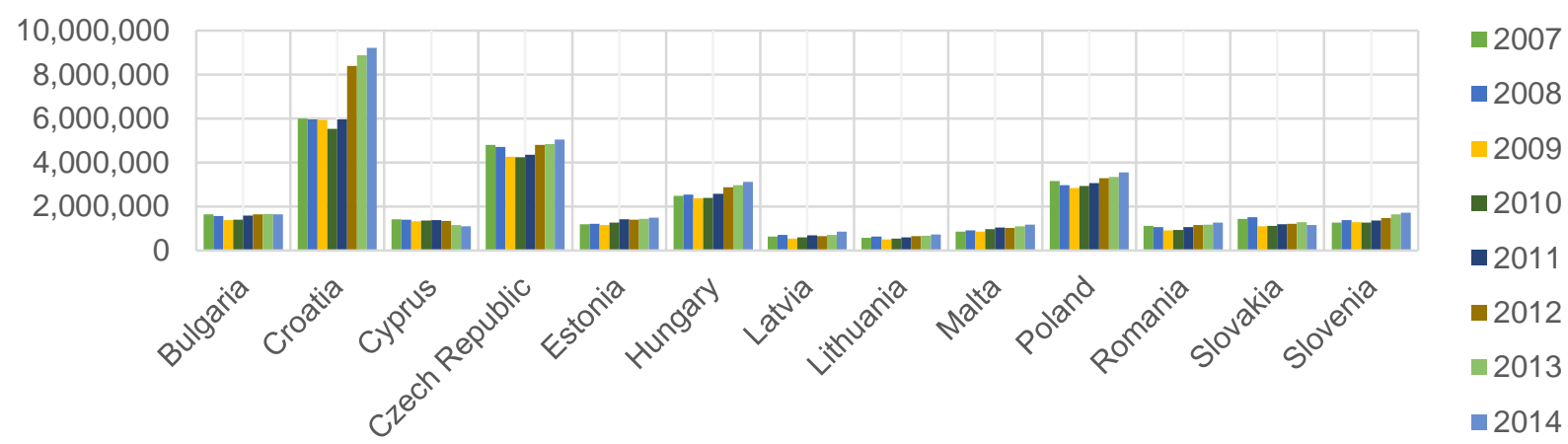

Figure 1. Evolution of EU arrivals in the NMS-13 by country of destination 2007-2014

Source: Authors' own research - based on data from Eurostat.

The main importers of tourism from the NMS-13 have been the residents of the Old Member States. Once the countries in Central Eastern and South Eastern Europe (CESEE) were declared eligible for EU accession, a sense of security and willingness to visit this region occurred, despite the negative perception about the countries in the area (Druvaskalne \& Slara, 2006). The top five countries whose citizens travelled to the NMS in the period 2007-2014 were Italy, Spain, France, Germany and the United Kingdom. 
Going further, residents of the NMS had a propensity to travel more than they used to do, but chose neighbouring countries. Citizens of Poland (12 million trips) and Czech Republic (10.4 million) travelled the most to the neighbourhood regions, within the NMS13 area, in the period 2007-2014.

The number of overnight stays is, as anticipated, in a tight relation with the number of arrivals, increasing by $20 \%$ in 2014 to 2007 (the number of EU arrivals went up by 16\%). One of the main explanations may be that the region of the NMS, was by that time an unexplored, new, unknown destination for many citizens of the EU. A study undertook by the European Commission back in 2003 (Tourism and the European Union) confirmed this supposition, revealing that " $75 \%$ of all EU citizens did not travel outside the European Union borders". Plus, considering that the NMS were not part of the EU in 2003, the EU accession can be considered an important trigger for the increasing figures both for intraEU overnight stays and intra-EU tourist arrivals, along with eased border crossing procedures, changes in transportation markets, tourism policies strengthening. The evolution of the number of EU overnight stays in the NMS-13 in the period 2007-2014 is presented in Figure 2.

\section{Evolution of EU-28 overnight stays in the NMS-13 2007-2014}

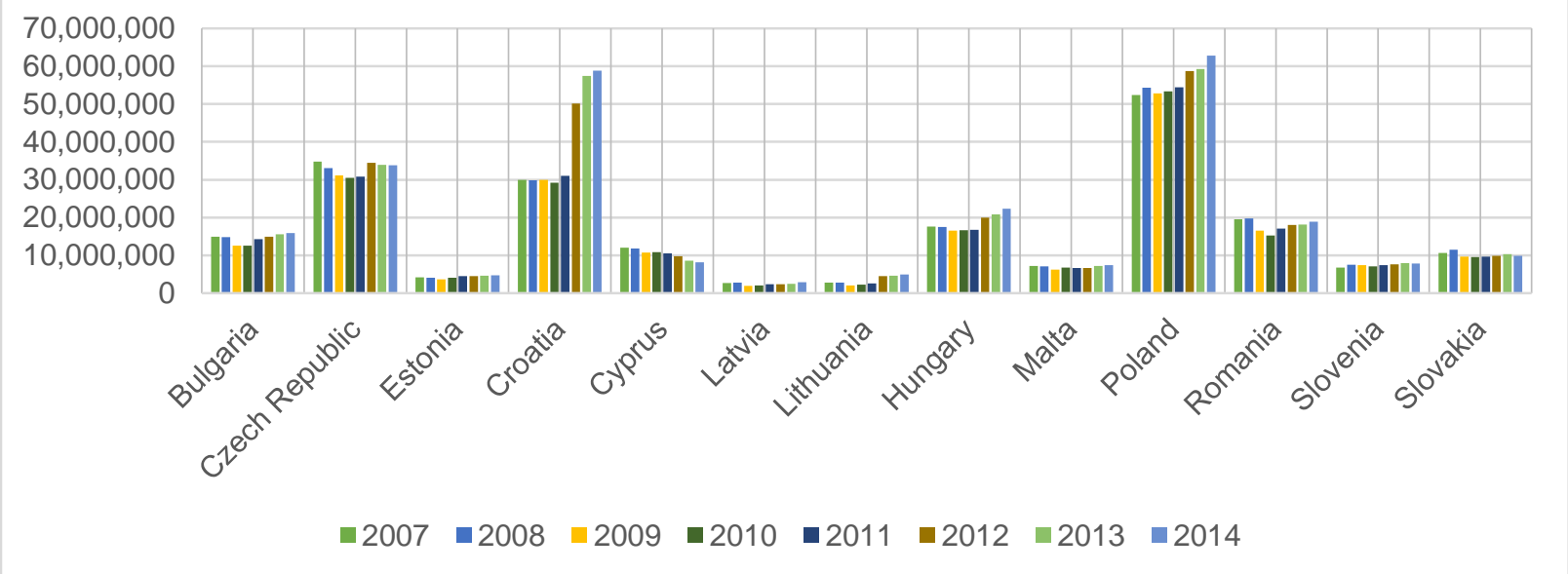

Figure 2. Evolution of EU-28 overnight stays in the NMS-13 2007-2014

Imports and Exports in the NMS-13

In regards to this set of indicators, imports and exports were considered to allow for a deeper understanding of tourism evolution in the context of EU enlargement waves, representing tourists' expenses for travel purposes.

Related to the amount of exports in travel, among the NMS, the ones that stand out were Poland, Croatia, Czech Republic and Hungary. Starting with 2004 when most of the NMS entered the EU, the exports in travel in the region significantly increased until 2009, and most of the overnight stays in the EU-28 were reported by Germany, UK and Italy. In 2013 exports in travel in the NMS were 66\% larger than in 2002, which in absolute terms implies that exports in the NMS-13 in 2013 were in amount of 39.2 thousand million. The travel imports reported by the NMS-13 almost doubled in 2013 compared to 2002.

Among the NMS-13, Poland and Czech Republic were the countries that imported travel services the most, the two countries together summing up half of the total imports in 
the NMS. As an explanation for this, the higher standard of living and average wages can be brought into discussion. Figure 3 exhibits best the evolution of imports and exports in the NMS in the period 2002-2013.

The difference between imports and exports could be explained by residents of the NMS' eagerness and curiosity to visit coupled with the openness of Western Europe to Central Eastern Europe (CEE), but also by the fact the unfavourable image the CEE PICBE | 499 countries had in the OMS. This reputation continues to act as a break factor for tourism industry in the CESEE region. Eased border crossing procedures, the upturning popularity of the "European identity" concept, GDP improvement and a continuously increasing desire and openness for travel are some other reasons that contributed to accelerated growth in terms of imports in the NMS and can definitely be attributed to the EU accession. According to Campos, Coricelli, \& Moretti (2014), approximately 12\% gain in the GDP per capita seemed to be directly related to being part of EU.

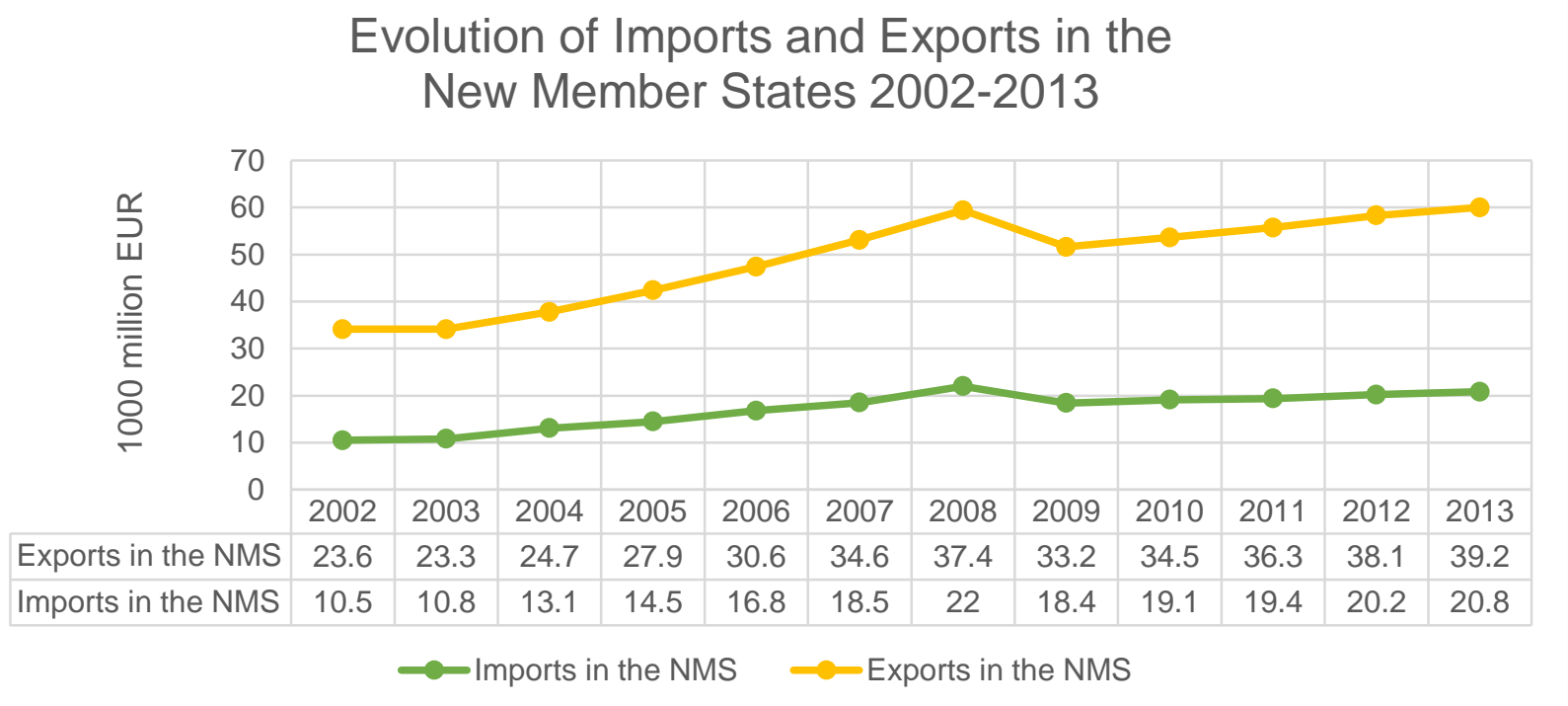

Figure 3. Evolution of Imports and Exports in NMS 2002-2013

Source: Authors' own research - based on data from Eurostat.

It is also interesting to notice which were the preferred countries for the residents of the NMS, but also where the incoming tourists in the NMS came from. In order to be able to sketch these two aspects, the number of arrivals, the number of overnight stays (by country of origin and country of destination) were looked at. Only countries from the EU were considered. Table 1 summarizes the findings.

Table 1. Preferred Countries of Destination and Main Sources of Tourists for the NMS-13

\begin{tabular}{|l|l|l|}
\hline NMS & Country of destination & Country of origin \\
\hline Bulgaria & Greece & Germany \\
\hline Czech Republic & Italy & Germany \\
\hline Estonia & Finland & Finland \\
\hline Croatia & Italy & Germany \\
\hline Cyprus & Greece & UK \\
\hline Latvia & UK & Germany \\
\hline
\end{tabular}




\begin{tabular}{|l|l|l|}
\hline Lithuania & UK & $\begin{array}{l}\text { Germany and Poland (approximately the } \\
\text { same number of tourists) }\end{array}$ \\
\hline Hungary & $\begin{array}{l}\text { Italy and Austria (approximately } \\
\text { the same number of tourists) }\end{array}$ & Germany \\
\hline Malta & UK & UK \\
\hline Poland & Italy & Germany \\
\hline Romania & Italy & $\begin{array}{l}\text { Germany and Italy (approximately the } \\
\text { same number of tourists) }\end{array}$ \\
\hline Slovenia & Croatia & Italy \\
\hline Slovakia & Czech Republic & Czech Republic \\
\hline
\end{tabular}

Source: Authors' own research - based on data from Eurostat.

Put in a nutshell, it seems that the sun and beach tourism represents the main tourism for travel in the EU, seconded by visits to relatives, family or friends (European Commission, 2015). Plus, approximately $15 \%$ of the total trips made within the time period analysed were for business purposes according to Eurostat, this number increasing yearly.

\section{Conclusions and main future challenges}

Tourism industry in the New Europe was highly influenced by the European integration process, but the long-term effects are yet to be observed and discussed. The main conclusions drawn based on the analysis conducted reflect the following:

a. Tourism is an important sector for the economy of the NMS, accounting for roughly $12 \%$ of their GDP, total contribution, while the direct contribution of travel and tourism to the NMS is approximately 5\% (World Travel \& Tourism Council, 2016).

b. Tourism industry is as a general perspective on an ascending path in the NMS. Yet, most of the NMS cannot actually compete or be compared with the OMS, as they lack infrastructure, have poorer marketing strategies and a smaller degree of international awareness concerning their touristic potential. The tourism sector was affected during the economic crisis period, but the CESEE region has now recovered and moderately positive trends have been reported.

c. As general trends and factors that affect tourism in the NMS-13 it was noticed that:

- there is a preference for trips to neighbouring countries, as a consequence of geographical proximity, presumably higher cultural similarity and reasonable prices

- business tourism is an important motivation for travel and accounts for a large proportion of the short stays, 1 to 3 days in the EU, while leisure trips still represent the highest incentive for travel for the residents of the NMS.

- the tourists from the NMS-13 that travel abroad in the EU choose either seaside and sunshine destinations and take a longer holiday or the capital cities for a city break

- the NMS countries that attracted the largest number of tourists are the ones situated in Central part of the continent and also the most economically 
developed, such as Poland and Czech Republic, but there is also Croatia, that offers seaside and sunshine tourism.

- diversification of tourism preferences of citizens in the OMS, the benefit of free movement, the increasing standard of living in the NMS, the growing desire to travel and consequently higher budgets designated for this activity, as well as the increasing business activities between the NMS and the OMS PICBE | 501 are among the most relevant factors that contributed to the growth of both incoming and outgoing tourism in the New Europe.

d. The European Institutions and the national authorities have been working together since 2007 to provide the NMS guidance, to help them reduce their vulnerabilities and increase competitiveness, to encourage co-operation, but also to raise awareness concerning their high touristic potential. The Western European citizens' eagerness and curiosity to discover new countries (less accessible by then) favoured the New Europe region, despite its unfavourable existing image. NMS represent the perfect destinations for the experienced tourists to fulfil their travel-related desires, to explore unique, exclusive places, where they can interact directly with local people, observe their traditions and have meaningful experiences. Increased tourism in EU, including in the NMS can contribute to the development of an European identity, as also identified by (Diaconescu, Nicolescu, \& Pânzaru, 2007).

It can be therefore stated that ever since the first year of accession, the EU managed to make a noticeable difference in the tourism industry for the group of NMS-13, but there is still ground for improvement and development, there are still countries that did not take full advantage of the opportunities offered. In the current economic and touristic context, community-based tourism, culinary tourism, agro-tourism, adventure tourism or cultural and religious tourism seem to be the segments that offer the best opportunities for tourism in the NMS.

\section{References}

Campos, N., Coricelli, F., and Moretti, L. (2014). How much do countries benefit from membership in the European Union? Retrieved from CEPR's Policy Portal: http://voxeu.org/article/how-poorer-nations-benefit-eu-membership.

Clerides, S., and Pashourtidou, N. (2007). Tourism in Cyprus: Recent Trends and Lessons from the Tourist Satisfaction Survey . Cyprus Economic Policy Review , 1(2). Nicosia, Cyprus.

Debyser, A. (2014). The European Union and tourism: challenges and policy responses. European Parliament, European Parliamentary Research Service. Retrieved from http://www.europarl.europa.eu/RegData/bibliotheque/briefing/2014/140749/LD M_BRI(2014)140749_REV1_EN.pdf.

Diaconescu, M., Nicolescu, L., and Pânzaru, F. (2007). The European Identity - between reality and hope. Romania within the EU: opportunities, requirements and perspectives. 1, pp. 135-141. Sibiu: Universitatea Lucian Blaga din Sibiu.

Directorate General Enterprise and Industry. (2012). European Tourism Label for Quality Systems Roadmap. Retrieved from European Commission: http://ec.europa.eu/smartregulation/impact/planned_ia/docs/2012_entr_020_european_tourism_label_en.pdf 
Directorate Sustainable Growth, DG Enterprise and Industry, Directorate Service Industries. (2013). Enhancing the Competitiveness of Tourism in the EU An Evaluation Approach to Establishing 20 Cases of Innovation and Good Practice. Centre for Strategy \& Evaluation Services, Kent.

Druvaskalne, I. D., and Slara, A. (2006). Tourism Challenges in the Baltic States Since EU Enlargement, Valmiera, Latvia. $\quad$ Retrieved $\quad$ from PICBE | 502 https://www.researchgate.net/publication/23731925_Tourism_Challenges_in_the_ Baltic_States_Since_EU_Enlargement.

Enterprise and Industry Directorate-General of the European Commission. (2007). The European Tourism Industry in the enlarged Community. Brussels.

European Commission. (2003). Communication from the Commision to the Council, the European Parliament, the European Economic and Social Committee and the Committee of the Regions - Basic Orientations for the Sustainability of European Tourism. Brussels, Belgium.

European Commission. (2010). Communication from the Commission to the European Parliament, the Council, the European Economic and Social Committee and the Committee of the Regions - Europe, the world's No 1 tourist destination - a new political framework for tourism in Europe. Brussels, Belgium.

European Commission. (2015). Flash Eurobarometer 414 Preferences of Europeans Towards Tourism. European Commission, Directorate-General for Internal Market, Industry, Entrepreneurship and SMEs, TNS Political \& Social . Brussels: European Commission.

European Commission. (2017). Low Season Tourism. Retrieved from http://ec.europa.eu/growth/sectors/tourism/offer/seniors-youth_en.

European Commission. (2010). Overview of EU Tourism Policy. Retrieved from https://ec.europa.eu/growth/sectors/tourism/policy-overview_en

European Commission. (2016). Overview of EU Tourism Policy. Retrieved from https://ec.europa.eu/growth/sectors/tourism/policy-overview/.

European Commission. (2003). Tourism and the European Union. Brussels, Belgium.

Eurostat. (2016). Expenditure by expenditure categories (from 2012 onwards). Retrieved from http://appsso.eurostat.ec.europa.eu/nui/show.do?dataset=tour_dem_exexp\& lang=en.

General Secretariat of the European Council and the Commission. (2008). The Lisbon Treaty. Consolidated Reader-Friendly Edition of the Treaty on European Union and the Treaty on the Functioning of the European Union as amended by the Treaty of Lisbon. (J.-P. Bonde, Ed.) Denmark: Foundation for EU Democracy.

General Secretariat of the European Council and the Commission. (1992). Treaty on European Union. Luxembourg, Luxemburg.

Laquidara, G. (2014). Low season tourism. Retrieved from http://ec.europa.eu/DocsRoom/documents/15162/attachments/1/translations.

Morata, F. (2002). Gobernanza multinivel en la Unión Europea. Lisboa, Portugal.

Nicolescu, L. (2008). Imaginea României sub lupă! Branding şi rebranding de ţară. Bucuresti, Romania: Editura ASE.

Nicolescu, L., Paun, C., Popescu, A. I., Draghici, A., and Pinzaru, F. (2007). National Identity An Essential Element for Country Branding. The Case of Romania. Review of Management and Economical Engineering , 6, 78-83. 
Statistical Service Republic of Cyprus. (2016). Tourism. Retrieved from http://www.cystat.gov.cy/mof/cystat/statistics.nsf/services_71main_en/services_7 1 main_en?OpenForm\&sub=1\&sel=2.

The Miroslav Krleža Institute of Lexicography. (2011). The Economy Tourism. Retrieved from http://croatia.eu/article.php?lang=2\&id=34.

United Nations World Tourism Organization. (2016). UNWTO Tourism Highlights. Tourism PICBE | 503 Market Trends Programme. Madrid: World Tourism Organization.

United Nations World Tourism Organization. (2016). UNWTO Annual Report 2015. Madrid: UNWTO.

Weiss, E., Weiss, R., Zuzik, J., \& Kovanic, L. (2013). Impact of economic crisis on tourism in Slovak Republic. Acta Geoturistica , 4, 10-14.

World Travel \& Tourism Council. (2016). Economic Impact Analysis Country Reports. Retrieved January 22, 2017, from The World Travel \& Tourism Council: http://www.wttc.org/research/economic-research/economic-impactanalysis/country-reports\#undefined. 